Rev. Biol. Neotrop. 5(1): 53-65, 2008

\title{
ARIAÇÃO ESTACIONAL DO ÓLEO ESSENCIAL EM ARNICA (LYCHNOFORA ERICOIDES MART.)
}

\author{
Marco Antônio Curado da Costa \\ José Garcia de Jesus \\ JoÃo Gaspar Farias \\ João Carlos Monh Nogueira \\ André Luiz Ribas de Oliveira
}

Escola de Agronomia e Engenharia de Alimentos, Universidade Federal de Goiás, Goiânia, Goiás, Brasil; e-mail: macurado@pop.com.br

\section{Pedro Henrique Ferri}

Laboratório de Bioquímica Molecular, Instituto de Química, Universidade Federal de Goiás, Goiânia, Goiás, Brasil; e-mail: pedro@quimica.ufg.br

\begin{abstract}
Resumo: Lychnophora ericoides Mart., comumente conhecida como arnica, vegeta em regiões de campos rupestres e pertence à família Asteraceae. No aspecto fármaco-terapêutico é empregada como antiinflamatório e anestésico, entre outras aplicações. Com o objetivo de encontrar o melhor período para a colheita, surgiu a necessidade de traçar o perfil sazonal do conteúdo do óleo essencial dessa planta, até o momento não identificado. Para isso, foram escolhidas duas áreas preservadas nos municípios de Cristalina e de Vianópolis, ambos situados no Estado de Goiás, Brasil. As coletas foram efetuadas no período entre julho de 2001 e julho de 2002. As amostras de cada acesso foram submetidas a extração por hidrodestilação, tendo sido encontrados 71 componentes no óleo essencial dessa planta. As amostras de óleo essencial extraídas foram analisadas por cromatografia gasosa acoplada a espectrometria de massa (CG-EM). As plantas coletadas em Cristalina apresentaram maiores teores de óleo em comparação com as de Vianópolis, com as maiores porcentagens nos meses de setembro de 2001 e novembro de 2001. Não se observou diferença significativa no teor de óleo das plantas em Vianópolis.
\end{abstract}

Palavras-chave: Arnica, Asteraceae, Lychnophora ericoides Mart., óleo essencial.

AвSTRACT: Lychnophora ericoides Mart., commonly known as arnica, is typical of campos rupestres and belongs to the family Asteraceae. In the farmacotherapeutic aspect it is used as anti-inflammatory and anesthetic among other applications. Aiming at defining the best period to collect the plant, it was necessary to trace the seasonal profile of the essential oil content, not identified so far. For that, preserved areas in Cristalina and Vianópolis, two cities located in the state of Goiás, in the Midwestern Region of Brazil were chosen. The plants were collected from July 2001 to July 2002. Samples of each area were submitted to extraction by hydrodistillation and 71 components were found in the essential oil of this plant. The samples of essential oil extracted were analyzed by gas chromatography-mass spectrometry (GC-MS). The plants collected in Cristalina presented higher amount of oil compared to the ones from Vianópolis, showing the highest percentages in September 2001 and November 2001. No significant difference was observed in oil content of the plants collected in Vianópolis.

KeY words: Arnica, Asteraceae, Lychnophora ericoides Mart., essential oil.

\section{INTRODUÇÃO}<smiles>[N]</smiles>

os últimos anos, o interesse pela exploração de plantas medicinais tem crescido substancialmente. Isso acarretou aumento da demanda por matéria-prima de qualidade e em quan- tidade suficiente para suprir a indústria farmacêutica, o consumo in natura ou a pesquisa de novos medicamentos. Em decorrência da importância estratégica desses recursos naturais, não é mais admissível a obtenção de matéria-prima por meio de extrativismo desordenado, sendo imprescindível a intro- 
dução de técnicas de coleta e de cultivo de espécies medicinais (Marques, 1998).

Entre as plantas comercializadas no país, a maior parte é de espécies nativas oriundas de atividade extrativista, as quais crescem espontaneamente nas mais diferentes formações vegetais. Entre elas encontra-se a arnica (Lychnophora ericoides Mart.), espécie já ameaçada de extinção (Nogueira \& Wolff, 2001).

O gênero Lychnophora Mart., pertencente à família Asteraceae, conta com cerca de 68 espécies, todas ocorrentes no Brasil (Santos et al., 2001). Entre elas está a arnica (Lychnophora ericoides Mart.), descrita por Martius em 1822 (Santos et al., 2001), também conhecida, popularmente, como arnica, candeia, pau de candeia, arnica da serra e falsa arnica. Essa planta é usada em medicina popular como analgésico e antiinflamatório (Santos et al., 2001). Ocorre em regiões montanhosas em alguns estados do Brasil e na Bolívia. Endêmica na América do Sul, típica de campos rupestres, desenvolve-se em áreas de afloramentos de rochas de quartzito ou arenito, baixo nível de fertilidade, de textura média a arenosa (Coile \& James, 1981 citados por Paron, 2002). Desse modo, grande parte dos nutrientes não se encontra na forma disponível para as plantas, fazendo com que seu desenvolvimento muitas vezes dependa de associações com microrganismos que as auxiliem em sua nutrição, como os fungos micorrízicos arbusculares (Paron, 2002). As espécies que formam a vegetação nessas regiões, em sua maioria nativas, foram selecionadas pelas condições adversas de solo e clima.

Os estudos sobre fisiologia, ecologia e biologia dessa espécie são escassos. Como a arnica é largamente utilizada em medicina popular e sujeita a coletas indiscriminadas, torna-se importante e urgente a obtenção de informações sobre o comportamento de seu óleo essencial e componentes químicos, visando o manejo adequado da espécie e o fornecimento de subsídios para coleta tecnificada, de modo a evitar seu desaparecimento.

Com o objetivo de encontrar o melhor momento para a coleta da planta, surgiu a necessidade de traçar um perfil sazonal do seu teor de óleo ao longo de um ano, bem como ampliar a investigação acerca de seus princi- pais componentes. Para tal, foram escolhidas duas áreas preservadas, com boa representação da população dessa espécie, nos municípios de Cristalina e Vianópolis, ambos situados no estado de Goiás.

\section{DESCRIÇÃO BOTÂNICA}

A arnica (Lychnophora ericoides Mart.) apresenta-se desde arbusto candelabriforme até arvoreta com 1,0 m a 3,0 m de altura; tem ramos alternos a subverticilados com indumento lanoso a subviloso candescente, variadamente acinzentado até cinza pardacento, com cicatrizes, formando alvéolos e dando aos ramos um aspecto tesselado, com cerca de 1,5 cm de diâmetro; as folhas são imbricadas na parte superior dos ramos patentes e de ápices mais reflexos abaixo, linear-lanceoladas, com base arredondada, ápice agudo e margem revoluta; apresentam venação broquidódroma, face adaxial glabra, ou tomentosa, ou pilosa quando jovem, nervura principal alargada na base afinando-se gradativamente para o ápice, bordos elevados, tornando-se sulcadas, com indumento tomentoso, face abaxial densamente serícea a vilosa, canescente a argêntea; seus ramos são parecidos com os galhos dos pinheiros (Pinus spp.), pouco ramificados (Corrêa, 1962); as flores são lilases a púrpura; as inflorescências apresentam-se em glomérulos simples, folhosos, hemisféricos; os capítulos são cilíndricos, com 3 a 5 flores, com $7,0 \mathrm{~mm}$ a $9,0 \mathrm{~mm}$ de comprimento e $0,3 \mathrm{~mm}$ a $0,5 \mathrm{~mm}$ de diâmetro; as brácteas são involucrais em quatro a cinco séries triangulares, ovais a oval-lanceoladas, com ápice obtuso a arredondado, margem lisa, superfície glandulosa, as maiores tendo de 7,0 a 8,0 mm de comprimento e 1,5 a 2,0 $\mathrm{mm}$ de largura; as anteras têm até 4,0 mm de comprimento; os aquênios são ocre a castanho-escuros, glabros, costados, angulosos, glandulosos, com $2,0 \mathrm{~mm}$ a $4,0 \mathrm{~mm}$ de comprimento e $1,0 \mathrm{~mm}$ a $1,5 \mathrm{~mm}$ de diâmetro; apresentam pappus externo livre, ceroso a agudo no ápice, com 2,0 $\mathrm{mm}$ a $4,0 \mathrm{~mm}$ de comprimento, pappus interno branco, muito caduco e variadamente paleáceo e espiralado, às vezes com um única espira, com cerca de 15 a 20 elementos, com $6,0 \mathrm{~mm}$ a $8,0 \mathrm{~mm}$ de comprimento (Leitão Filho \& Semir, 1979; Semir, 1991; Silva, 1994). 
A espécie Lychnophora ericoides Mart. é caracterizada por um notável endemismo, habitando principalmente regiões montanhosas com afloramentos rochosos de quartzito ou arenito em campo rupestre, com altitudes entre $800 \mathrm{~m}$ a $2.000 \mathrm{~m}$ e solos com pH ácido, ocorrendo nos estados de Bahia, Espírito Santo, Goiás, Minas Gerais, São Paulo e também no Distrito Federal (Almeida et al., 1998; Leite \& Del-Vechio, 2000; Santos et al., 2001; Silva, 1994).

Atualmente, a arnica encontra-se na categoria de plantas vulneráveis ou ameaçadas de extinção (Silva, 1994).

USO TERAPÊUTICO

O uso de espécies nativas pode ser uma alternativa econômica para o aproveitamento sustentável de certas regiões. Várias são as espécies que possuem utilização regional e muitas delas enquadram-se em mais de um tipo de indicação. Entretanto, de acordo com Ribeiro et al. (1994 citados por Almeida et al., 1998), o usuário mais freqüente desse tipo de produto ainda é a população regional e seu modo de obtenção é essencialmente extrativista. Segundo o autor, foi possível confirmar as propriedades farmacológicas de várias espécies usadas na medicina popular, demonstradas pelas análises químicas e biológicas. No entanto, apesar de bastante promissor, esse campo ainda se ressente da falta de estudos farmacológicos. Os mesmos autores citam ainda a arnica como planta ornamental, embora seja pouco utilizada por paisagistas, talvez pela falta de conhecimento de seu manejo.

A arnica fornece madeira branca e dura, cujo peso específico é 0,886 g.cm³ (Corrêa, 1962), resinosa e com boa superfície para o envernizamento, características próprias para sua utilização como esteio e em cercas em lugares úmidos, além de obras de torno, palitos, coronhas de espingardas, lenha e carvão.

Nas ruas da maioria das cidades do país é comum encontrar bancas, barracas ou carrinhos com ampla diversidade de espécies de plantas medicinais. Pode-se perceber que famílias inteiras são mantidas com recursos gerados do extrativismo de plantas às quais se atribuem propriedades medicinais, muitas oriundas do Cerrado.
Sob o aspecto farmaco-terapêutico, a arnica é empregada em machucados, contusões, inchaços, como antiinflamatório, aromatizadora (Almeida et al., 1998), anestésico, cicatrizante e no tratamento de hematomas. As partes da planta mais utilizadas são as folhas e os ramos (Cerqueira et al., 1987; Pinto et al., 2000; Santos et al., 2001).

Empresas de cosméticos e farmácias de manipulação têm fabricado e comercializado sabonetes, extratos alcoólicos e pomadas que contêm arnica em sua formulação e são comercializadas com fins terapêuticos, alguns sem pesquisa alguma.

Os erveiros, com seu conhecimento empírico, comentam que a arnica só está boa para coleta pouco antes e pouco depois da floração, quando as folhas liberam um óleo pegajoso. Assim, é importante determinar, com base em pesquisas científicas, o período em que a planta contém maior teor de substâncias com atividades analgésicas e antiinflamatórias.

\section{COMPONENTES QUÍMICOS}

Lopes (2001) comprovou as propriedades analgésicas e antiinflamatórias da arnica brasileira (Lychnophora ericoides Mart.) e encontrou nessa espécie três substâncias, tendo duas propriedades antiinflamatórias e uma, analgésica, com atividade farmacológica comprovada. Naquele estudo, o autor determinou que várias substâncias antiinflamatórias são armazenadas nas raízes e nas folhas e muitas substâncias analgésicas estão presentes nas raízes da planta; por outro lado, não foi encontrado nenhum composto de interesse farmacológico no caule. Entre as mais de 50 substâncias encontradas nos diferentes extratos, as duas mais importantes foram um antiinflamatório encontrado nas folhas e a lignana cubenina, com atividade analgésica, presente nas raízes. Outros antiinflamatórios que apresentaram goiasenolido e centraterina foram testados diretamente sobre as proteínas associadas ao processo inflamatório e também apresentaram bons resultados.

De acordo com Santos et al. (2001), quase a totalidade dos estudos fitoquímicos realizados com Lychnophora ericoides Mart. empregaram extratos de polaridade média das folhas, principalmente diclorometânicos. Estudos 
demonstram a predominância de lactonas sesquiterpênicas, triterpenos e flavonóides (Cabral et al., 2000; Pinto et al., 2000).

Santos et al. (2001) conseguiram isolar uma saponina diglicosilada, a chikusetsusaponina, pela primeira vez revelando a ocorrência desta classe de compostos na espécie Lychnophora ericoides Mart. Cabral et al. (2000) identificaram os esteróides estigmasterol, $\beta$-sitosterol e campesterol, com atividade antiinflamatória, no caule da arnica.

As folhas da arnica apresentam diversos grupos químicos, como flavonóides, leucoantocianidinas, esteróides, triterpenos, taninos e saponinas, identificados por Leite \& Del-Vechio (2000). Sua casca é tanífera e as folhas e flores são aromáticas e medicinais (Corrêa, 1962).

A International Standard Organization (ISO) define óleos voláteis como produtos obtidos de partes de plantas utilizando destilação por arraste de vapor d'água. De forma geral, são misturas complexas de substâncias voláteis, lipofílicas, geralmente odoríferas e líquidas. Também podem ser chamadas de óleos essenciais e sua principal característica é a volatilidade, diferindo, assim, dos óleos fixos, mistura de substância lipídicas. Outra característica importante é o aroma intenso da maioria dos óleos voláteis, solúvel em solventes orgânicos apolares, como éter etílico. Outras características são: sabor, cor e estabilidade. Em geral, os óleos voláteis não são muito estáveis, principalmente em presença de ar, luz, calor, umidade e metais; a maioria dos óleos voláteis apresenta índice de refração e são opticamente ativos. Seus constituintes variam desde hidrocarbonetos terpênicos, aldeídos, fenóis, éteres, óxidos, peróxidos e ácidos orgânicos até compostos com enxofre em diferentes concentrações.

Segundo Teuscher (1990 citado por Simões \& Spitzer, 2000), a composição do óleo volátil de uma planta é determinada geneticamente, sendo geralmente específica para um determinado órgão e característica para o seu estágio de desenvolvimento; porém, as condições ambientais são capazes de causar variações significativas. Em uma determinada espécie, a concentração de cada um dos constituintes dos óleos voláteis pode variar durante o desenvolvimento do vegetal.
Os métodos de extração variam conforme a localização do óleo volátil na planta e com a proposta de sua utilização. Os mais comuns são: enfloração, arraste por vapor d'água, extração com solventes orgânicos, prensagem e extração por $\mathrm{CO}_{2}$ supercrítico. Os óleos voláteis devem ser guardados dessecados (secos com $\mathrm{Na}_{2} \mathrm{SO}_{4}$ anidro) e livres de impurezas insolúveis.

\section{MATERIAIS E MÉTOdos}

\section{LOCAIS DE COLETA}

As coletas foram efetuadas bimestralmente durante o período de um ano, em duas áreas, situadas nos municípios de Vianópolis e Cristalina, ambos no estado de Goiás, nos dias 26 de julho de 2001, 27 de setembro de 2001, 27 de novembro de 2001, 31 de janeiro de 2002, 28 de março de 2002, 27 de maio de 2002 e 20 de julho de 2002. Cada localidade foi dividida em três acessos.

As plantas encontradas na região de Cristalina não apresentam aroma, suas folhas são menores e de coloração verde, têm hábito ereto-tortuoso, são ramificadas e delicadas. Em Vianópolis, apresentam aroma agradável e característico, as folhas são maiores, com grande quantidade de escamas, de cor verdeprateada e as plantas são eretas e robustas.

A análise e o estudo do solo foram executados para melhor caracterizar os locais de coleta. Também foi elaborada uma exsicata com duplicatas, as quais foram registradas e depositadas no Herbário da Universidade Federal de Goiás (UFG 27.033).

Foram coletadas apenas as folhas, pois além de estudos anteriores sobre Lychnophora ericoides Mart. terem evidenciado predomínio de óleo nesta parte da planta (Cabral et al., 2000), neste estudo procurou-se evitar grandes danos às plantas. $\mathrm{O}$ material coletado foi encaminhado ao Laboratório de Bioatividade Molecular do Instituto de Química da UFG e seguiu as normas de conduta indicadas por Ferri (1995).

As amostras foram compostas por uma pequena quantidade de folhas de vários indivíduos, para cada data de coleta, totalizando 36 amostras no final do período de um ano. 
As amostras dos espécimes representativas de cada acesso, dentro das populações, foram dessecadas à temperatura ambiente durante sete dias. Após fragmentação, o material botânico foi submetido a extração por hidrodestilação (com água destilada) em aparelho do tipo Clevenger, modificado, por 5 horas. $\mathrm{O}$ óleo essencial foi recolhido, seco com $\mathrm{Na}_{2} \mathrm{SO}_{4}$ anidro e acondicionado em frascos de vidro, etiquetado, pesado e armazenadosem congelador $\left(-18^{\circ} \mathrm{C}\right)$ até ser analisado.

A hidrodestilação do óleo essencial de arnica produziu um óleo de coloração amarelo-clara e transparente com aroma agradável.

CONSIDERAÇÕES SOBRE O SOLO

O relevo em Cristalina apresenta-se suavemente ondulado, o solo é característico de campo rupestre com afloramentos rochosos em arenito, apresentando uma sequência de lajes rochosas e a textura do solo é Areia Franca.

Em Vianópolis, o relevo é acidentado, apresentando grande declividade, porém sem afloramentos rochosos e a textura do solo é Franco Arenosa.
As características químicas e físicas dos solos coletados em Cristalina e Vianópolis, analisadas no Laboratório de Análise de Solo e Foliar da Escola de Agronomia da UFG, em 2002, são apresentadas na Tabela 1.

Para as classes texturais dos solos analisados, o elemento potássio apresenta-se com baixo teor nos dois locais (Embrapa, 1999). O pH dos dois solos é considerado fortemente ácido. O teor do elemento cálcio para os dois solos é baixo. O magnésio é considerado médio para o solo de Cristalina e baixo para o solo de Vianópolis. A saturação de alumínio é muito alta para os dois solos. A saturação de bases é média para o solo de Cristalina e baixa para o solo de Vianópolis (Comissão de Fertilidade de Solos de Goiás, 1988).

\section{AvALIAÇÃO DA COMPOSIÇÃO QUÍMICA DO ÓLEO}

As amostras de óleo essencial foram submetidas a análise por cromatografia gasosa acoplada a espectrometria de massa (CG/EM) em um equipamento modelo QP5050A (Shimadzu Corp., Japão).

Tabela 1 - Características químicas e físicas das amostras de solos coletadas em Cristalina e Vianópolis, Goiás.

\begin{tabular}{|c|c|c|}
\hline Característica do solo & Cristalina & Vianópolis \\
\hline Argila (dag.dm ${ }^{-3}$ ) & 10,33 & 18,30 \\
\hline Silte (dag.dm $\left.{ }^{-3}\right)$ & 2,67 & 22,10 \\
\hline Areia $\left(\right.$ dag. $\left.\mathrm{dm}^{-3}\right)$ & 87,00 & 59,60 \\
\hline Matéria orgânica (dag.dm³) & 5,83 & 1,40 \\
\hline $\mathrm{pH}\left(\mathrm{CaCl}_{2}\right)$ & 4,13 & 4,13 \\
\hline $\mathrm{pH}\left(\mathrm{H}_{2} \mathrm{O}\right)$ & 4,73 & 4,73 \\
\hline P Mehlich (mg.dm³) & 6,25 & 2,83 \\
\hline $\mathrm{K}\left(\mathrm{mg} \cdot \mathrm{dm}^{-3}\right)$ & 0,05 & 0,07 \\
\hline $\mathrm{Ca}\left(\mathrm{cmol}_{\mathrm{c}} \cdot \mathrm{dm}^{-3}\right)$ & 0,45 & 0,50 \\
\hline $\operatorname{Mg}\left(\mathrm{cmol}_{c} \cdot \mathrm{dm}^{-3}\right)$ & 0,19 & 0,10 \\
\hline $\mathrm{Ca}+\mathrm{Mg}\left(\mathrm{cmol}_{c} \cdot \mathrm{dm}^{-3}\right)$ & 0,64 & 0,60 \\
\hline $\mathrm{H}+\mathrm{Al}\left(\mathrm{cmol}_{\mathrm{c}^{\prime}} \cdot \mathrm{dm}^{-3}\right)$ & 1,73 & 6,57 \\
\hline $\mathrm{Al}\left(\mathrm{cmol}_{\mathrm{c}} \cdot \mathrm{dm}^{-3}\right)$ & 0,89 & 1,75 \\
\hline CTC $\left(\mathrm{cmol}_{\mathrm{c}} \cdot \mathrm{dm}^{-3}\right)$ & 2,35 & 7,16 \\
\hline Saturação de bases (\%) & 26,28 & 8,63 \\
\hline Saturação de $\mathrm{Al}$ (\%) & 53,59 & 73,50 \\
\hline $\mathrm{Ca} / \mathrm{Mg}$ & 2,89 & 4,50 \\
\hline $\mathrm{Mg} / \mathrm{K}$ & 2,93 & 1,45 \\
\hline $\mathrm{Ca} / \mathrm{K}$ & 7,71 & 4,75 \\
\hline
\end{tabular}


A identificação dos componentes do óleo essencial foi realizada por comparação (automática e manual) com aqueles constantes da biblioteca do National Institute of Standards of Technology (NIST) e também por comparação de seus espectros de massa e índices de retenção calculados com os valores encontrados na literatura para os componentes mais comuns de óleos essenciais (Adams, 1995, 2001).

\section{AnÁLISE ESTATÍSTICA}

A variabilidade sazonal da composição química do óleo essencial foi efetuada por meio da análise multifatorial utilizando o software Statistical Analysis System (SAS) do SAS Institute Inc/EUA. O experimento foi avaliado como multifatorial, sendo os fatores o local, as coletas e três repetições.

Acomparação de médias foi realizada pelo teste de Tukey a 5\% de significância. Em decorrência da heterogeneidade regular dos dados foi necessária sua transformação; para isso, somouse 0,5 aos valores observados e posteriormente extraiu-se a raiz quadrada, apresentando-os, assim, em uma distribuição aproximadamente normal (Banzatto \& Kronka, 1992).

\section{Resultados e discussão}

\section{RENDIMENTO DO ÓLEO ESSENCIAL}

A extração do óleo essencial das plantas de arnica coletadas foi realizada no laboratório de química de produtos naturais do Instituto de Química da UFG.
O rendimento do óleo essencial foi calculado com o uso da fórmula:

sendo:

$$
\mathrm{Rd}=(\mathrm{Mo} / \mathrm{Os}) \times 100
$$

$\mathrm{Rd}=$ Rendimento do óleo essencial (\%)

Mo = Massa de óleo essencial extraído $(\mathrm{g})$

Os $=$ Peso seco da amostra vegetal $(\mathrm{g})$

Os rendimentos do óleo essencial extraído das amostras estão apresentados na Tabela 2, podendo-se observar que os obtidos das plantas de Cristalina foram significativamente superiores àqueles das plantas de Vianópolis.

Os rendimentos de óleo essencial não diferiram significativamente entre as épocas de coleta em Vianópolis, ao passo que em Cristalina apresentaram diferenças estatisticamente significativas, tendo seu pico inicial em junho de 2001 e seu ápice em setembro de 2001, decaindo após este período (Figura 1).

Identificação dos compostos do óleo essencial de Lychnophora ericoides Mart.

Os resultados das análises para a identificação dos componentes da mistura de óleo essencial, extraído das amostras de arnica coletadas em Cristalina e Vianópolis, podem ser observados na Tabela 3 e Tabela 4, respectivamente, de acordo com a seqüência de ebulição em coluna CBP-5.

Entre os componentes determinados nas amostras de arnica analisadas, foram observados 16 que se apresentaram em maiores quantidades, cujas estruturas estão representadas na Figura 2.

Tabela 2 - Rendimento de óleos essenciais extraídos de plantas de arnica em função da época e do local de coleta.

\begin{tabular}{lcc}
\hline \multirow{2}{*}{ Época } & \multicolumn{2}{c}{ Rendimento de óleos essenciais (\%) } \\
\cline { 2 - 3 } & Cristalina & Vianópolis \\
\hline Julho 2001 & $0,86 \mathrm{Ab}$ & $0,77 \mathrm{Ba}$ \\
Setembro 2001 & $1,89 \mathrm{Aa}$ & $0,80 \mathrm{Ba}$ \\
Novembro 2001 & $1,09 \mathrm{Aab}$ & $0,82 \mathrm{Ba}$ \\
Janeiro 2002 & $0,87 \mathrm{Ab}$ & $0,79 \mathrm{Ba}$ \\
Março 2002 & $0,91 \mathrm{Ab}$ & $0,74 \mathrm{Ba}$ \\
Maio 2002 & $0,91 \mathrm{Ab}$ & $0,86 \mathrm{Ba}$ \\
Julho 2002 & $0,87 \mathrm{Ab}$ & $0,77 \mathrm{Ba}$ \\
\hline
\end{tabular}

Médias seguidas da mesma letra não diferem entre si pelo teste de Tukey a 5\% de significância; as letras maiúsculas representam comparação de médias para o local (na horizontal); as letras minúsculas representam comparação de médias para as épocas (na vertical). 


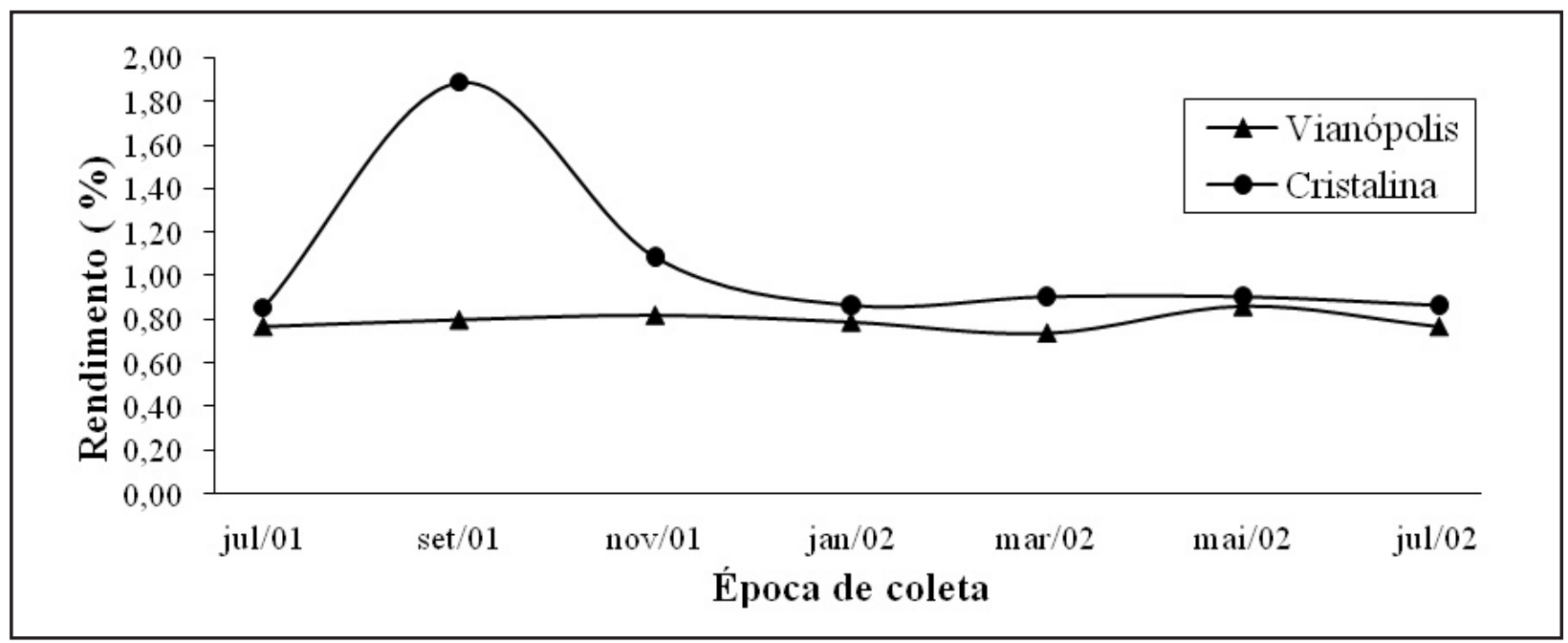

Figura 1 - Rendimento de óleos essenciais extraídos de plantas de arnica em função da época e do local de coleta.

Tabela 3 - Componentes dos óleos essenciais com seus respectivos índices de retenção calculados de amostras de arnica coletadas em Cristalina e citados na literatura.

\begin{tabular}{|c|c|c|c|c|c|c|}
\hline \multirow{2}{*}{$\begin{array}{l}\text { Componente } \\
\left(\mathrm{N}^{\mathrm{o}} \text {-nome) }\right.\end{array}$} & \multirow{2}{*}{$\mathbf{I R}^{\mathrm{a}}$} & \multirow{2}{*}{$\mathbf{I R}^{\mathrm{b}}$} & \multirow{2}{*}{ Média } & \multirow{2}{*}{ Desvio-padrão } & \multicolumn{2}{|c|}{ Valores } \\
\hline & & & & & Mínimo & Máximo \\
\hline 1-Tricicleno & 932 & 926 & 3,28 & 2,12 & 0,77 & 11,94 \\
\hline 2-Benzaldeído & 954 & 960 & 0,04 & 0,10 & 0,00 & 0,37 \\
\hline 3- pineno & 974 & 979 & 1,06 & 0,46 & 0,56 & 2,78 \\
\hline 4- -terpineno & 1.014 & 1.017 & 0,48 & 0,24 & 0,01 & 0,91 \\
\hline 5-o-cimeno & 1.021 & 1.026 & 2,79 & 2,18 & 0,37 & 9,96 \\
\hline 6-Limonene & 1.026 & 1.029 & 2,05 & 1,21 & 0,88 & 6,60 \\
\hline 7- terpineno & 1.056 & 1.060 & 1,73 & 0,58 & 1,10 & 3,74 \\
\hline 8-Terpinoleno & 1.086 & 1.089 & 0,25 & 0,15 & 0,01 & 0,63 \\
\hline 9-Desconhecido & 1.091 & & - & - & - & - \\
\hline 10-Linalool & 1.098 & 1.097 & 2,76 & 1,49 & 1,05 & 7,18 \\
\hline 11-Desconhecido & 1.102 & & 0,27 & 0,26 & 0,01 & 1,04 \\
\hline 12-Desconhecido & 1.119 & & 0,01 & 0,01 & 0,00 & 0,04 \\
\hline 13-Desconhecido & 1.127 & & 0,00 & 0,00 & 0,00 & 0,01 \\
\hline 14-trans-pinocarveol & 1.136 & 1.139 & 0,00 & 0,00 & 0,00 & 0,01 \\
\hline 15-Pinocarvona & 1.159 & 1.165 & 0,00 & 0,00 & 0,00 & 0,01 \\
\hline 16-Borneol & 1.163 & 1.169 & 0,07 & 0,14 & 0,00 & 0,63 \\
\hline 17-Terpinen-4-ol & 1.175 & 1.177 & 4,35 & 2,02 & 0,72 & 10,14 \\
\hline 18- -terpineol & 1.189 & 1.189 & 1,11 & 0,53 & 0,15 & 2,84 \\
\hline 19-Mirtenol & 1.194 & 1.196 & 0,00 & 0,00 & 0,00 & 0,01 \\
\hline 20-Silfiperfol-5-ene & 1.324 & 1.329 & 0,89 & 0,45 & 0,04 & 2,19 \\
\hline 21-Presilfiperfol-7-ene & 1.332 & 1.337 & 1,87 & 0,68 & 0,87 & 3,55 \\
\hline 22-7-epi-silfiperfol-5-ene & 1.343 & 1.348 & 2,01 & 0,86 & 0,64 & 4,37 \\
\hline 23-Silfiperfol-6-ene & 1.375 & 1.379 & 0,72 & 0,26 & 0,28 & 1,38 \\
\hline 24- maalieno & 1.379 & 1.382 & 0,15 & 0,34 & 0,00 & 1,37 \\
\hline
\end{tabular}


Tabela 3 - Continuação.

\begin{tabular}{|c|c|c|c|c|c|c|}
\hline \multirow{2}{*}{$\begin{array}{l}\text { Componente } \\
\text { ( } \mathrm{N}^{\mathrm{o}} \text {-nome) }\end{array}$} & \multirow{2}{*}{$\mathrm{IR}^{\mathrm{a}}$} & \multirow{2}{*}{$\mathbf{I R}^{\mathrm{b}}$} & \multirow{2}{*}{ Média } & \multirow{2}{*}{ Desvio-padrão } & \multicolumn{2}{|c|}{ Valores } \\
\hline & & & & & Mínimo & Máximo \\
\hline 25 -isocomeno & 1.386 & 1.388 & 0,05 & 0,13 & 0,00 & 0,51 \\
\hline 26-Desconhecido & 1.391 & & 0,03 & 0,05 & 0,00 & 0,16 \\
\hline 27-Desconhecido & 1.397 & & 0,00 & 0,00 & 0,00 & 0,01 \\
\hline 28-Desconhecido & 1.413 & & 0,08 & 0,09 & 0,00 & 0,29 \\
\hline 29-(E)-cariofileno & 1.418 & 1.419 & 2,73 & 1,26 & 0,92 & 5,75 \\
\hline 30-Desconhecido & 1.429 & & 0,11 & 0,11 & 0,00 & 0,38 \\
\hline 31--humuleno & 1.452 & 1.455 & 0,57 & 0,31 & 0,00 & 1,25 \\
\hline 32-Desconhecido & 1.466 & & 0,00 & 0,00 & 0,00 & 0,01 \\
\hline 33- acoradieno & 1.477 & 1.471 & 1,59 & 0,77 & 0,73 & 3,54 \\
\hline 34- r-curcumeno & 1.480 & 1.481 & 1,05 & 0,34 & 0,36 & 1,88 \\
\hline 35-Desconhecido & 1.497 & & 0,46 & 0,16 & 0,01 & 0,77 \\
\hline 36-Silfiperfolan-6-a-ol & 1.503 & 1.508 & 0,14 & 0,12 & 0,00 & 0,33 \\
\hline 37-Cameroonan-7-a-ol & 1.507 & 1.512 & 2,94 & 0,99 & 1,24 & 4,77 \\
\hline 38-Silfiperfolan-7-b-ol & 1.51 .5 & 1.521 & 0,86 & 0,67 & 0,01 & 2,50 \\
\hline 39-Desconhecido & 1.520 & & 0,74 & 0,21 & 0,01 & 1,01 \\
\hline 40-Italiceno éter & 1.532 & 1.538 & 0,27 & 0,15 & 0,01 & 0,62 \\
\hline 41-Desconhecido & 1.539 & & 1,54 & 0,85 & 0,01 & 3,42 \\
\hline 42-Desconhecido & 1.549 & & 0,49 & 0,35 & 0,01 & 1,16 \\
\hline 43-(E)-nerolidol & 1.564 & 1.563 & 41,74 & 9,81 & 19,94 & 60,46 \\
\hline 44-Desconhecido & 1.570 & & 0,37 & 0,29 & 0,00 & 0,97 \\
\hline 45-Desconhecido & 1.573 & & - & - & - & - \\
\hline 46- r-turmerol & 1.576 & 1.583 & 0,41 & 0,19 & 0,01 & 0,77 \\
\hline 47-Óxido de cariofileno & 1.582 & 1.583 & 1,78 & 0,60 & 0,55 & 2,98 \\
\hline 48-Desconhecido & 1.585 & & 0,19 & 0,47 & 0,00 & 2,28 \\
\hline 49- r-dihidro-turmerona & 1.596 & 1.596 & 9,71 & 3,91 & 3,46 & 20,01 \\
\hline 50-Desconhecido & 1.600 & & 0,23 & 0,18 & 0,00 & 0,52 \\
\hline 51-Desconhecido & 1.608 & & 0,53 & 0,20 & 0,01 & 0,82 \\
\hline 52-Desconhecido & 1.613 & & 0,72 & 0,44 & 0,00 & 1,64 \\
\hline 53-Desconhecido & 1.617 & & 0,31 & 0,24 & 0,00 & 0,76 \\
\hline 54-Desconhecido & 1.623 & & 0,19 & 0,15 & 0,00 & 0,45 \\
\hline 55-Eremoligenol & 1.632 & 1.631 & 0,01 & 0,03 & 0,00 & 0,11 \\
\hline 56-Desconhecido & 1.634 & & 0,25 & 0,20 & 0,00 & 0,62 \\
\hline $\begin{array}{l}\text { 57-Epóxi-allo-aroma- } \\
\text { dendreno }\end{array}$ & 1.638 & 1.641 & 0,03 & 0,08 & 0,00 & 0,34 \\
\hline 58-Desconhecido & 1.642 & & 0,26 & 0,21 & 0,00 & 0,60 \\
\hline 59- -cadinol & 1.646 & 1.654 & 0,01 & 0,05 & 0,00 & 0,24 \\
\hline 60-Desconhecido & 1.657 & & 0,14 & 0,19 & 0,00 & 0,63 \\
\hline 61-Desconhecido & 1.661 & & 0,00 & 0,00 & 0,00 & 0,01 \\
\hline 62-Desconhecido & 1.664 & & 0,05 & 0,07 & 0,00 & 0,19 \\
\hline
\end{tabular}


Tabela 3 - Continuação.

\begin{tabular}{lcccccc}
\hline $\begin{array}{l}\text { Componente } \\
\text { (N }\end{array}$ & IR $^{\mathbf{a}}$ & IR $^{\mathbf{b}}$ & Média & Desvio-padrão & & \multicolumn{2}{c}{ Valores } \\
\hline 63-Desconhecido & 1.670 & & 0,24 & 0,24 & Mínimo & Máximo \\
64-epi-a-bisabolol & 1.682 & 1.685 & - & - & 0,00 & 0,89 \\
65- -Bisabolol & 1.685 & 1.686 & - & - & - & - \\
66-Desconhecido & 1.687 & & 0,47 & 1,14 & 0,00 & 5,20 \\
67-Desconhecido & 1.691 & & 0,25 & 0,22 & 0,00 & 0,85 \\
68-Kusimol & 1.723 & 1.736 & 0,00 & 0,00 & 0,00 & 0,01 \\
69-(E)- Atlantona & 1.727 & 1.707 & 0,02 & 0,03 & 0,00 & 0,14 \\
70-(6S,7R)-Bisabolona & 1.745 & 1.750 & 1,52 & 1,22 & 0,00 & 5,81 \\
71-Benzoato de benzila & 1.760 & 1.760 & 0,06 & 0,09 & 0,00 & 0,28 \\
\hline
\end{tabular}

a Índice de retenção calculado de acordo com Dool e Kratz (1963).

b índice de retenção segundo Adams (1995). Os componentes 9, 46, 65 e 66 possuem média igual a zero.

Tabela 4 - Componentes dos óleos essenciais com seus respectivos índices de retenção calculados de amostras de arnica coletadas em Vianópolis e citados na literatura.

\begin{tabular}{|c|c|c|c|c|c|c|}
\hline \multirow{2}{*}{$\begin{array}{l}\text { Componente } \\
\left(\mathrm{N}^{\circ} \text {-nome) }\right.\end{array}$} & \multirow{2}{*}{$\mathrm{IR}^{\mathrm{a}}$} & \multirow{2}{*}{$\mathbf{I R}^{\mathrm{b}}$} & \multirow{2}{*}{ Média } & \multirow{2}{*}{ Desvio-padrão } & \multicolumn{2}{|c|}{ Valores } \\
\hline & & & & & Mínimo & Máximo \\
\hline 1-Tricicleno & 932 & 926 & 1,67 & 0,87 & 0,32 & 3,95 \\
\hline 2-Benzaldeído & 954 & 960 & 0,06 & 0,11 & 0,00 & 0,42 \\
\hline 3- pineno & 974 & 979 & 0,80 & 0,35 & 0,19 & 1,59 \\
\hline 4- -terpineno & 1.014 & 1.017 & 0,18 & 0,13 & 0,01 & 0,52 \\
\hline 5-o-cimeno & 1.021 & 1.026 & 2,08 & 0,88 & 0,89 & 4,24 \\
\hline 6-Limonene & 1.026 & 1.029 & 0,67 & 0,29 & 0,00 & 1,35 \\
\hline 7- terpineno & 1.056 & 1.060 & 0,47 & 0,23 & 0,18 & 1,16 \\
\hline 8-Terpinoleno & 1.086 & 1.089 & 0,08 & 0,09 & 0,00 & 0,29 \\
\hline 9-Desconhecido & 1.091 & & 0,08 & 0,10 & 0,00 & 0,37 \\
\hline 10-Linalool & 1.098 & 1.097 & 0,73 & 0,32 & 0,00 & 1,71 \\
\hline 11-Desconhecido & 1.102 & & 0,53 & 0,28 & 0,08 & 1,39 \\
\hline 12-Desconhecido & 1.119 & & 0,05 & 0,07 & 0,16 & 0,25 \\
\hline 13-Desconhecido & 1.127 & & 0,07 & 0,11 & 0,00 & 0,40 \\
\hline 14-trans-pinocarveol & 1.136 & 1.139 & 0,19 & 0,23 & 0,00 & 0,85 \\
\hline 15-Pinocarvona & 1.159 & 1.165 & 0,07 & 0,10 & 0,00 & 0,33 \\
\hline 16-Borneol & 1.163 & 1.169 & 0,04 & 0,08 & 0,00 & 0,35 \\
\hline 17-Terpinen-4-ol & 1.175 & 1.177 & 1,69 & 0,80 & 0,00 & 3,77 \\
\hline 18- -terpineol & 1.189 & 1.189 & 0,78 & 0,45 & 0,01 & 2,31 \\
\hline 19-Mirtenol & 1.194 & 1.196 & 0,25 & 0,24 & 0,01 & 0,78 \\
\hline 20-Silfiperfol-5-ene & 1.324 & 1.329 & 0,06 & 0,10 & 0,01 & 0,33 \\
\hline 21-Presilfiperfol-7-ene & 1.332 & 1.337 & - & - & - & - \\
\hline 22-7-epi-silfiperfol-5-ene & 1.343 & 1.348 & - & - & - & - \\
\hline 23-Silfiperfol-6-ene & 1.375 & 1.379 & - & - & - & - \\
\hline 24- maalieno & 1.379 & 1.382 & 0,04 & 0,10 & 0,00 & 0,35 \\
\hline 25 -isocomeno & 1.386 & 1.388 & - & - & - & - \\
\hline
\end{tabular}


Tabela 4 - Continuação.

\begin{tabular}{|c|c|c|c|c|c|c|}
\hline \multirow{2}{*}{$\begin{array}{l}\text { Componente } \\
\left(\mathrm{N}^{\circ} \text {-nome }\right)\end{array}$} & \multirow{2}{*}{$\mathbf{I R}^{\mathrm{a}}$} & \multirow{2}{*}{$\mathbf{I R}^{\mathrm{b}}$} & \multirow{2}{*}{ Média } & \multirow{2}{*}{ Desvio-padrão } & \multicolumn{2}{|c|}{ Valores } \\
\hline & & & & & Mínimo & Máximo \\
\hline 26-Desconhecido & 1.391 & & - & - & - & - \\
\hline 27-Desconhecido & 1.397 & & 0,05 & 0,09 & 0,00 & 0,31 \\
\hline 28-Desconhecido & 1.413 & & - & - & - & - \\
\hline 29-(E)-cariofileno & 1.418 & 1.419 & 0,01 & 0,05 & 0,00 & 0,22 \\
\hline 30-Desconhecido & 1.429 & & - & - & - & - \\
\hline 31--humuleno & 1.452 & 1.455 & - & - & - & - \\
\hline 32-Desconhecido & 1.466 & & 0,05 & 0,07 & 0,00 & 0,28 \\
\hline 33- acoradieno & 1.477 & 1.471 & 0,53 & 0,46 & 0,00 & 1,64 \\
\hline 34-r-curcumeno & 1.480 & 1.481 & 1,03 & 0,39 & 0,01 & 1,95 \\
\hline 35-Desconhecido & 1.497 & & 0,04 & 0,19 & 0,00 & 0,89 \\
\hline 36-Silfiperfolan-6-a-ol & 1.503 & 1.508 & 0,06 & 0,20 & 0,00 & 0,88 \\
\hline 37-Cameroonan-7-a-ol & 1.507 & 1.512 & 0,01 & 0,03 & 0,00 & 0,13 \\
\hline 38-Silfiperfolan-7-b-ol & 1.51 .5 & 1.521 & 1,95 & 0,77 & 0,12 & 3,47 \\
\hline 39-Desconhecido & 1.520 & & 0,02 & 0,07 & 0,00 & 0,30 \\
\hline 40-Italiceno éter & 1.532 & 1.538 & 0,30 & 0,15 & 0,01 & 0,62 \\
\hline 41-Desconhecido & 1.539 & & - & - & - & - \\
\hline 42-Desconhecido & 1.549 & & 0,05 & 0,11 & 0,00 & 0,45 \\
\hline 43-(E)-nerolidol & 1.564 & 1.563 & 0,10 & 0,11 & 0,00 & 0,35 \\
\hline 44-Desconhecido & 1.570 & & 0,20 & 0,07 & 0,00 & 0,32 \\
\hline 45-Desconhecido & 1.573 & & - & - & - & - \\
\hline 46- r-turmerol & 1.576 & 1.583 & 0,93 & 0,39 & 0,27 & 1,89 \\
\hline 47-Óxido de cariofileno & 1.582 & 1.583 & 0,55 & 0,22 & 0,00 & 1,00 \\
\hline 48-Desconhecido & 1.585 & & - & - & - & - \\
\hline 49- r-dihidro-turmerona & 1.596 & 1.596 & 0,37 & 0,29 & 0,00 & 1,10 \\
\hline 50-Desconhecido & 1.600 & & 0,05 & 0,21 & 0,00 & 0,99 \\
\hline 51-Desconhecido & 1.608 & & 0,25 & 0,32 & 0,00 & 1,58 \\
\hline 52-Desconhecido & 1.613 & & 0,94 & 0,40 & 0,00 & 1,62 \\
\hline 53-Desconhecido & 1.617 & & 0,22 & 0,25 & 0,00 & 0,84 \\
\hline 54-Desconhecido & 1.623 & & 0,00 & 0,00 & 0,00 & 0,01 \\
\hline 55-Eremoligenol & 1.632 & 1.631 & - & - & - & - \\
\hline 56-Desconhecido & 1.634 & & 0,80 & 0,15 & 0,00 & 0,40 \\
\hline $\begin{array}{l}\text { 57-Epóxi-allo-aromaden- } \\
\text { dreno }\end{array}$ & 1.638 & 1.641 & - & - & - & - \\
\hline 58-Desconhecido & 1.642 & & 0,00 & 0,02 & 0,00 & 0,09 \\
\hline 59--cadinol & 1.646 & 1.654 & 17,34 & 4,84 & 8,02 & 25,51 \\
\hline 60-Desconhecido & 1.657 & & - & - & - & - \\
\hline 61-Desconhecido & 1.661 & & 0,15 & 0,16 & 0,00 & 0,53 \\
\hline
\end{tabular}


Tabela 4 - Continuação.

\begin{tabular}{lcccccc}
\hline $\begin{array}{l}\text { Componente } \\
\text { (N }\end{array}$ & $\mathbf{I R}^{\mathbf{a}}$-nome) & $\mathbf{I R}^{\mathbf{b}}$ & Média & Desvio-padrão & \multicolumn{2}{c}{ Valores } \\
\cline { 5 - 7 } 62-Desconhecido & 1.664 & & - & - & Mínimo & Máximo \\
63-Desconhecido & 1.670 & & 0,13 & 0,19 & - & - \\
64-epi-a-bisabolol & 1.682 & 1.685 & - & - & 0,01 & 0,58 \\
65- -Bisabolol & 1.685 & 1.686 & 61,53 & 10,56 & - & - \\
66-Desconhecido & 1.687 & & 1,44 & 0,59 & 0,63 & 81,29 \\
67-Desconhecido & 1.691 & & 0,00 & 0,00 & 0,00 & 0,01 \\
68-Kusimol & 1.723 & 1.736 & 0,04 & 0,09 & 0,00 & 0,32 \\
69-(E)- Atlantona & 1.727 & 1.707 & 0,00 & 0,00 & 0,00 & 0,01 \\
70-(6S,7R)-Bisabolona & 1.745 & 1.750 & 0,12 & 0,15 & 0,00 & 0,52 \\
71-Benzoato de benzila & 1.760 & 1.760 & 0,11 & 0,16 & 0,00 & 0,56 \\
\hline
\end{tabular}

a Índice de retenção calculado de acordo com Dool e Kratz (1963).

b índice de retenção segundo Adams (1995). Os componentes 9, 46, 65 e 66 possuem média igual a zero.<smiles>CC1(C)C2CC3CC1C3(C)C2</smiles>

Tricicleno<smiles>Cc1ccccc1C(C)C</smiles>

o-Cimeno<smiles>C=C(C)C1CC=C(C)CC1</smiles>

Limoneno<smiles>CC1=CCC(O)(C(C)C)CC1</smiles>

Terpinen-4-ol<smiles>CC1=CCC(C(C)(C)O)CC1</smiles>

$\alpha$-Terpineol<smiles>C=C1CC/C=C(/C)CC[C@H]1C1CC1(C)C</smiles>

(E) Cariofileno<smiles>CC(C)=CCCC(C)c1ccc(C)cc1</smiles>

$\alpha$-Curcumeno

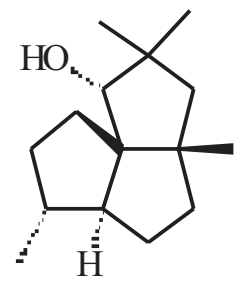

Cameroonan-7-a-ol<smiles>C[C@H]1CCC23[C@H]1CC[C@@](C)(C[C@H]2C)C3(O)O</smiles>

Silfiperfolan-7-b-ol<smiles>C=CC(C)(O)CCC=C(C)CCC=C(C)C</smiles>

(E) Nerolidol<smiles>CC(C)=CC(O)CC(C)c1ccc(C)cc1</smiles>

$\alpha r$-Turmerol<smiles>C=CC(=O)CC(C)c1ccc(C)cc1</smiles>

$\alpha$-r-dihidroTurmerona<smiles>CC1=C[C@H]2CCC[C@@H](O)[C@H]2CC1</smiles>

$\alpha$-Cadinol<smiles>CC(C)=CCCC(C)(O)[C@H]1CC=C(C)CC1</smiles>

$\alpha$-Bisabolol

Figura 2 - Estrutura quimica dos principais componentes dos óleos essenciais das folhas de Lychnophora ericoides Mart., segundo Adams (1995). 


\section{Conclusões}

Em relação ao perfil do óleo essencial determinado em plantas de arnica, foram encontrados 71 componentes, dos quais 29 não têm padrão disponível na literatura para sua identificação.

As plantas coletadas em Cristalina apresentaram maior teor percentual de óleo e o componente presente em maior quantidade naquele município foi (E)-nerolidol, enquanto em Vianópolis foi -bisabolol.

As coletas realizadas em Cristalina apresentaram maior teor de óleo nos meses de setembro de 2001 e novembro de 2001, diferindo significativamente das demais épocas. Nesse município, o maior rendimento em óleo ocorreu em outubro, configurando, portanto, a época mais adequada para a colheita da arnica.

Não houve diferenças significativas entre as coletas realizadas em Vianópolis.Assim, a coleta das plantas pode ser feita durante o ano todo nesse município, pois não há oscilação estacional na produção do óleo essencial.

\section{REFERÊNCIAS}

Adams, R. P. 1995. Identification of essential oil components by gas chromatography/ quadrupole mass spectroscopy. Alured Publishing Corporation, Carol Stream, $468 \mathrm{p}$.

Adams, R. P. 2001. Identification of essential oil components by gas chromatography / mass spectroscopy. Alured Publishing Corporation, Carol Stream, $456 \mathrm{p}$.

Almeida, S. P., C. E. B. Proença, S. M. Sano \& J. F. Ribeiro. 1998. Cerrado. Espécies vegetais úteis. EMBRAPA-CPAC, Planaltina.

Banzatto, D. A \& S. N. Kronka. 1992. Experimentação agrícola. UNESP, Jaboticabal, 247 p.

Cabral, A. C. S., N. P. Lopes \& J. L. C. Lopes. 2000. Terpenóides do tronco de Lychnophora ericoides Mart. In: XVI Simpósio de plantas medicinais do Brasil. Recife. Resumos. p. 134.

Cerqueira, M. B. S., J. T. Souza, R. Amado Junior \& A. B. F. Peixoto. 1987. Ação anal- gésica do extrato bruto aquoso liofilizado do caule e folhas da Lychnophora ericoides Mart. (arnica). Ci. Cult. 35: 551-553.

Comissão de Fertilidade de Solos de Goiás. 1988. Recomendações de corretivos e fertilizantes para Goiás: $5^{\mathrm{a}}$ aproximação. UFG/EMGOPA, Goiânia, 101 p. (Informativo Técnico, 1).

Corrêa, M. P. 1962. Dicionário das plantas úteis do Brasil e das exóticas cultivadas. 6 a . ed. Imprensa Nacional, Rio de Janeiro, vol I, 431 p.

Embrapa. 1999. Manual de análises químicas de solos, plantas e fertilizantes. Embrapa Solos, Embrapa Informática Agropecuária, Embrapa comunicação para transferência de tecnologia, Brasília, DF, 370 p.

Ferri, P. H. 1995. Química de produtos naturais: métodos gerais, p. 129-156. In: Di Stasi, L. C. Plantas medicinais: arte e ciência. Um guia de estudo interdisciplinar. São Paulo, Ed. Universidade Estadual de Paulista.

Dool, H. van den \& P. D. J. Kratz. 1963. A generalization of the retention index system including linear temperature progammed gas-liquid partition chromatography. J. Chromatogr. 11: 463.

Leite, M. N. \& G. Del-Vechio. 2000. Contribuição para o estudo farmacognóstico de Lychnophora ericoides. In: XVI Simpósio de plantas medicinais do Brasil, Recife, Resumos. p. 185.

Leitão Filho, H. F. \& J. Semir. 1979. Uma nova contribuição para o gênero Vernonia Schreb. (Compositae). Rev. Bras. Bot. 2: 113-116.

Lopes, N. P. A essência da arnica. 2001. Pesq. FAPESP, São Paulo, 64: 42-44. (Suplemento Especial).

Marques, F. C. 1998. Análise da qualidade de sementes e do crescimento inicial de marcela Achyrocline saturioides Lam. D. C. (Asteraceae), p. 43-70. In: Ming, L.C., M.C. Scheffer, C. Correa Júnior, I.B.I. Barros \& J.K.A. Mattos (Eds), Plantas medicinais aromáticas e condimentares: Avanços na pesquisa agronômica. Botucatu, Universidade Estadual Paulista, v. 1. 
Nogueira, J. C. M. \& C. K. Wolff. 2001. Na luta pela produção socialmente saudável. Que remédio? Acúmulos, riscos e potenciais na inter-relação entre plantas medicinais e agricultura familiar. Candeia, I: 26-29.

Paron, M. E. 2002. Diversidade de fungos micorrízicos arbuscuslares em Lychnophora ericoides Mart. (Arnica da Serra): efeito da inoculação e estudos de propagação. Jaboticabal, Faculdade de Ciências Agrária e Veterinária, Universidade de São Paulo. 99 f, Tese de Doutorado em Microbiologia.

Pinto, J. E. B. P., E. A. Santiago \& O. A. Lameira. 2000. Compêndio de plantas medicinais. Lavras: UFLA/FAEPE, 208 p.

Ribeiro, J. F. \& B. M. T. Walter. 1998. Fitofisionomias do bioma Cerrado, p. 89-166. In: S. M. Sano \& S. P. Almeida (Eds), Cerrado: ambiente e flora. Planaltina, EMBRAPACPAC.
Santos, M. D., L. Gobbo Neto, C. Pizza \& N. P. Lopes. 2001. Estudos fitoquímicos do extrato polar das raízes de Lychnophora ericoides Mart. In: XVI Simpósio de plantas medicinais do Brasil. Resumos. Recife, UFPE.

Semir, J. 1991. Revisão taxonômica de Lychnophora Mart. (Vernoniaceae: Compositae). Campinas, SP, Instituto de Biologia, Universidade de Campinas. 515 f, Tese de Doutorado em Ciências Biológicas.

Silva, S. M. P. 1994. Aspectos da fenologia e da reprodução sexuada da Lychnophora pinaster Mart. - Asteraceae. Lavras, Universidade Federal de Lavras. 40 f, Dissertação de Mestrado em Agronomia.

Simões, C. M. O. \& V. Spitzer. 2000. Óleos voláteis, p. 387-415. In: Simões, C. M. O., E. P. Schenkel, G. Gosmann, J. C. P. Mello, L. A. Mentz \& P. R. Petrovick. (Orgs), Farmacognosia: da planta ao medicamento. $2^{\text {a }}$ ed. ver. Porto Alegre, Ed. UFRGS, Ed. UFSC.

Recebido em 24/I/2006

Aceito em 2/IX/2008 
